\title{
Reactionary Rhetoric Against Open Access Publishing
}

\author{
Wayne Bivens-Tatum \\ Princeton University, Princeton NJ, USA, rbivens@princeton.edu, \\ http:// blogs.princeton.edu/librarian
}

\begin{abstract}
In 2013, Jeffrey Beall published an attack on the open-access scholarship movement in tripleC: "The Open-Access Movement Is Not Really About Open Access". This article examines the claims and arguments of that contribution. Beall's article makes broad generalizations about openaccess advocates with very little supporting evidence, but his rhetoric provides good examples of what Albert O. Hirschman called the "rhetoric of reaction". Specifically, it provides examples of the perversity thesis, the futility thesis, and the jeopardy thesis in action. While the main argument is both unsound and invalid, it does show a rare example of reactionary rhetoric from a librarian.
\end{abstract}

Keywords: Open-access, Scholarly publishing, Reactionary, Rhetoric

You should realize that when Joseph Esposito (2013) at the generally anti-open access Scholarly Kitchen blog thinks your anti-open access rant is excessive, you've crossed some sort of threshold. You should also realize that when Michael Eisen (2013) of the Public Library of Science bothers to give your article a thorough fisking, you have people's attention. In the digital pages of this very open access journal, Jeffrey Beall (2013) managed to publish an anti-open access article so poorly argued that I wonder if he'll later use the publication as an example of how bad open access (OA) publishing can be. If only Lingua Franca were still around to publish "The Beall Hoax".

\section{Broad Generalisations with No Evidence}

Beall makes a number of outrageous claims about $O A$ advocates without referring to or citing any of them. There's absolutely no evidence presented that any OA advocates hold any of the "anti-corporatist" (sic) views that Beall attributes to them, which leaves the article as an eight-page rant against a straw target. Beall $(2013,590)$ claims that "a close analysis of the discourse of the OA advocates reveals that the real goal of the open access movement is to kill off the for-profit publishers and make scholarly publishing a cooperative and socialistic enterprise". That close analysis never comes. If it had come, this article would be a serious contribution to the OA discussion instead of an uninformative rant, especially if it had analysed representative passages from numerous OA advocates instead of cherry-picking juicy but unrepresentative quotes from a handful of alleged zealots. It wouldn't have proved anything against OA itself, but it might have made for a good read and would have been less cringe-worthy.

Because the argument is unsupported and so extreme, all I have to do to prove it wrong is to say I'm an open access advocate who doesn't support the elimination of private corporations or commercial publishers or the suppression of freedom of the press or any of the other nonsense views he attributes to people like me. I'm not a socialist or a collectivist or any of the other favourite adjectives Beall wants to label me with. And, unlike some people I might mention, I'm not a zealot. There, thesis disproved.

\section{Slight Attempts to Engage Actual OA Advocates}

While it's true that the extremely broad and hostile generalisations about OA advocates come with no supporting evidence, Beall does refer to two pieces of writing by OA advocates, and his language regarding them is worth considering. For example, in response to a 
New York Times article (Kolata 2013) on "predatory publishers" (heavily reliant upon Beall's views), David Bollier (2013) criticised the article and suggested, based on evidence from another writer's analysis of other pieces of writing by the reporter, that the Times writer was biased towards corporate science publishers in her reporting. His main claim, though, is that while such "predatory publishers exist, "the idea that the Public Library of Science and other OA journals are somehow responsible for these scams is absurd". And, of course, that is an absurd claim, although that doesn't prevent Beall $(2013,591)$ from making it repeatedly. Beall considers this a "perhaps slightly paranoid blog post". It didn't read as paranoid to me, but if you're an OA advocate, even if you're not paranoid, Jeffrey Beall is still out to get you.

The second small encounter with an actual OA advocate is with Stevan Harnad (2013), who wrote an article arguing among other things that, based on the evidence, the stronger an OA mandate from an institution is, the more likely researchers will deposit articles in its institutional repository, and thus, being the "collectivist" OA advocate that he is, he suggests that institutions adopt stronger mandates regarding their institutional repositories. The strongest requirement Harnad would like to see is this one: "the institutional repository must be designated as the sole mechanism for submitting publications for institutional performance evaluation, research grant applications and national research assessment' (Harnard 2013, emphasis in original). Nothing precludes publishing in non-OA journals, though. That's my take on the article.

Beall's $(2013,593)$ take is slightly more, well, paranoid: "Open access advocates think they know better than everyone else and want to impose their policies on others" (593). So one alleged problem with OA advocates is that they think they know better than everyone else. I could also point to one anti-OA advocate guilty of that common sin. Also, "the open access movement has the serious side-effect of taking away other's freedom from them". Here we get an example of what I will later analyse as reactionary perversity rhetoric in action: open access takes people's freedom away. Their freedom to do what isn't entirely clear. It seems from context that an institution paying a researcher to do research and expecting that researcher to deposit the results in an institutional repository is somehow totalitarian. Harnad (2013) presents mandates of various strengths from "no requirement: just request, recommendation, or encouragement" to "immediate deposit + performance evaluation (no waiver option)". Notice that the most stringent mandate is that researchers have to deposit in an institutional repository. Beall deems this an "Orwellian system of mandates" (594). Even an attempt to examine actual evidence elicits hyperbolic rhetoric rather than close analysis. Beall's $(2013,594)$ conclusion is that "a social movement that needs mandates to work is doomed to fail", although if it's "bound to fail", then why bother penning such a screed? Supposedly, "a social movement that uses mandates is abusive and tantamount to academic slavery". So it's Orwellian, abusive, and basically slavery. You'd think that researchers were forced to work for free or be in danger of having their faces chewed off by rats.

\section{The Rhetoric of Reaction}

The arguments in the article, such as they are, are weak and unsupported, so attempting to engage with them is impossible. Instead, I want to look at the reactionary rhetoric, because Beall's article is an unusual example of that from a librarian. For people who have read a lot of conservative literature, the clues to a reactionary worldview are evident throughout the article. For example, Beall $(2013,590)$ claims that "the open access movement and scholarly open-access publishing itself are about increasing managerialism". Eisen (2013) had to look that up, but if he were familiar with mid-twentieth century conservative political writer James Burnham, he would have known about Burnham's 1941 book The Managerial Revolution. Burnham, a long-time contributor to the National Review, was once upon a time quite prominent in conservative circles. Along with the unfounded accusations about people being collectivists wanting to destroy private enterprise, Burnham's work was hot among the right in the 1950s.

This reactionary bit should sound familiar to anyone who has read the Manichaen apocalyptic novelist often taken for a political philosopher by teenage boys, Ayn Rand. "The open- 
access movement is really about anti-corporatism. OA advocates want to make collective everything and eliminate private business, except for small businesses owned by the disadvantaged" (Beall 2013, 589). How did we get from wanting open access for scholarly publishing to wanting to eliminate all private businesses? Or this: "The open-access movement isn't really about open access. Instead, it is about collectivizing production and denying the freedom of the press from those who prefer the subscription model of scholarly publishing" (Beall $2013,596)$. How does publishing some material in an openly accessible form prevent other people from publishing other material and trying to charge for it? How do we get from one of these to the other? I can tell you how we don't get there: through an analysis of any writings by OA advocates. A movement devoted to open access literature is denying freedom of the press? That's perversity in action.

However, this makes some sense if you share a Randian worldview. In this comforting worldview, the world is a simple place to understand. It's filled not with flawed human beings acting upon a variety of motivations trying to make their way through a complex existence. No, the world is made of heroes and villains. The heroes are the people who think as I do and are always right. The villains are any people who disagree with any part of my ideology. They do so not because the world is complicated and disagreement natural, but because they are evil and possibly stupid, and no matter what noble motives they might claim to have, they're lying and trying to destroy some beloved institution. Also, there's the faith that commercial enterprise is always good and free markets (if they ever really exist) always lead to the best outcome. Challenging this faith in any way leads to an extreme reaction. Criticizing any area in which private enterprise and free markets maybe don't give us the outcomes we want is equated with being a "collectivist" who wants to bring the capitalist system down. That explains why in the article, criticism of Elsevier or of commercial science publishing means that one wants to destroy all corporations. It doesn't make a lot of sense until you look at it through the Randian lens.

In this world, people don't support open access because they think the creation and dissemination of new knowledge is a public good. They do it because they want to destroy all corporations and deny freedom to people. This must be their motive because they disagree with Beall about open access scholarship, and he thinks these things are bad, so they must be motivated by these evil ideas. Q.E.D. Since there have to be heroes and villains, Beall must be the hero and everyone who disagrees with him in the slightest a villain who is acting from evil motives to destroy everything he holds dear. Once you share this worldview, evidence doesn't matter anymore.

The rhetoric throughout is so supercharged with hostility that it's impossible to take seriously unless you already absolutely agree with everything written. Much of it follows the pattern laid out by Albert Hirschman. In his book The Rhetoric of Reaction: Perversity, Futility, Jeopardy, Albert O. Hirschman (1991) analyses right-wing rhetoric from the French Revolution on and finds three persistent types of argument.

I have come up with another triad: that is, with three principal reactive-reactionary theses, which I call the perversity thesis or thesis of the perverse effect, the futility thesis, and the jeopardy thesis. According to the perversity thesis, any purposive action to improve some feature of the political, social, or economic order only serves to exacerbate the condition one wishes to remedy. The futility thesis holds that attempts at social transformation will be unavailing, that they will simply fail to "make a dent". Finally, the jeopardy thesis argues that the code of the proposed chafe or reform is too high as it endangers some previous, precious accomplishment. (7)

Beall manages to deploy all these rhetorical moves in the course of his article. Let's take a look at some passages trying to find the perversity, futility, and jeopardy theses.

It's likely that hundreds or even thousands of honest researchers have fallen prey to the predatory publishers, those open-access publishers that exploit the gold 
open-access model just for their own profit, pretending to be legitimate publishing operations but actually accepting any and all submissions just for the money (Beall 2013, 591)

Notice the "it's likely". That's as close as we get to evidence. Although weak on evidence, this is a good example of the perversity thesis in action. Predatory gold-OA publishers exist and they exploit people and harm scholarly publishing, and it's all the fault of OA advocates. This isn't what the OA advocates promised us! This is bad! We can all agree that it's bad, but it takes a special kind of logic to say that because some bad people do bad things with OA that all OA is thus bad. Governments issue people driver's licenses. People die in automobile accidents. Thus, the governments are responsible for those people dying. Q.E.D.

One of the headings in the article claims that "Gold Open Access is Failing". As Eisen (2013) notes, "this is the worst form of cherry-picking. Open access publishing is 'failing' because one open access publisher that published an insignificant number of papers went out of business?". Not really much evidence for it, but it might be an example of the futility thesis. Nothing good will come from OA scholarly publishing. It's a futile effort that will merely result merely in more "predatory" publishers. Beware OA publishing! He futility reaction is pointless. If something you don't like is failing, why bother to express such public hostility against it? Let it fail.

The jeopardy thesis is pervasive. Scholarship is in jeopardy because of predatory publishers. Public access to good science is in jeopardy because of [...] predatory publishers. The tenure process for young scholars is in jeopardy because "some tenured open-access advocates are pressuring young scholars away from submitting their work to traditional journals, sacrificing them to the open-access movement" (593). We don't know who these tenured open-access advocates or pressured young scholars are because none of them are named, so we'll just have to take Beall's word for it.

Oh, and the careers of scientists in developing countries are also in jeopardy. "OA advocates are also pressuring scientists in developing countries to publish in OA journals, and this could hurt their careers" (593). Again, we're not told who these pressured scientists are. That quote is supposedly supported by a citation from an article by Jorge Contreras on OA science publishing in the developing world, which itself is citing the quote from yet another source. Beall writes that,

According to Contreras $(2012,60)$, scientists in the developing world wish to publish in prestigious venues, with the greatest likely readership. Artificially forcing them to publish in OA journals of lesser impact could be resented and resisted, as it would be in the industrialized world (Beall 2013, 593).

Except that's not "according to Contreras". That's the opinion of Padmanabhan Balaram, the Director of the Indian Institute of Technology, whom Contreras cites. Unsurprisingly, Beall stops quoting there, because here's the very next sentence (that really is according to Contreras):

Given the challenges faced by researchers in the developing world, is OA publishing likely to advance their scientific work in a meaningful way? The answer is almost certainly "Yes," though not without effort, and not without adjustments to traditional ways of thinking about scientific research and publishing (Contreras, $61)$.

That's the beginning of a conclusion that goes on to advocate several changes that would help OA science publishing benefit scientists in the developing world even more than Contreras believes they have already benefitted from it. Where Beall's response is to damn all OA publishing because of the allegedly predatory actions of some gold OA publishers, Contreras $(2012,61)$ suggests sensible changes like implementing "better systems to differentiate 
among developing world OA journals on the basis of quality". That would pretty much take care of the "predatory publisher" problem.

So from a long article about the various ways OA publishing could be improved, by a researcher who has concluded that overall even the developing world benefits from OA science publishing, Beall focuses completely on the potential harm suggested by one source and ignores the remedies. Instead of considering Contreras' conclusions and arguing against them, Beall $(2013,593)$ merely claims that "OA advocates also want to sacrifice the careers of developing-world scholars so that they can achieve their collectivist goals". Yes, oh yes, that's what OA advocates want! Sacrificing careers! Achieving collectivist goals! Reading that, I imagine Beall wandering the streets with a lighted candle trying to find one OA advocate who really wants to sacrifice scholarly careers.

The free-market perfection of commercial science publishing is in jeopardy from gold-OA as well. "The act of instituting financial transactions between scholarly authors and scholarly publishers is corrupting scholarly communication. This was one of the great benefits of the traditional scholarly publishing system-it had no monetary component in the relationship between publishers and their authors" (Beall 2013, 593). You see, adding a "money component" is what leads to "predatory publishers", and "predatory publishers" are bad. On the other hand, there are OA advocates, including me, who believe gold-OA is problematic, just not for the reasons Beall claims.

If Beall fairly considered the evidence for and against both traditional publishing and OA publishing, or even acknowledged the obvious fact that commercial scholarly publishing has some problems, it might be possible to engage in a discussion, but that's impossible here. A careful thinker of Beall's persuasion would have argued that OA publishing has some unintended harmful effects, and perhaps would have tried to prove that "predatory publishers" were an effect of OA publishing, although that's still not a very strong argument. Instead of doing that, Beall assumes that OA publishing is bad for various reasons and then attributes bad intentions to OA advocates. Even if OA publishing led to the disastrous consequences Beall claims, which it doesn't, the idea that any OA advocates actually want to suppress the freedom of the press or to harm scholarly careers or create some "Orwellian" system is so absurd that the article falls apart.

\section{Conclusion}

I've analysed the rhetoric because of the lack of arguments and evidence supporting the claims about OA advocates, but there seems to be a certain logic to Beall's overall mission. Here's the argument in syllogistic terms as I infer it:

- Major premise: All predatory publishing is bad publishing.

- Minor premise: Some OA publishing is predatory publishing.

- Conclusion: Therefore, all OA publishing is bad publishing.

The problem is, that's an invalid argument. A term distributed in the conclusion must also be distributed in a premise for the argument to be valid. Traditionally, a term is "distributed" when it applies to every type of thing it mentions. In this syllogism, "OA publishing" is distributed in the conclusion but not in the minor premise. The move from "some OA publishing" to "all OA publishing" is invalid.

Informally, the argument fails because the sweeping generalizations with no supporting evidence render it unsound. Formally, the argument fails because its improperly distributed terms when in syllogistic form render it invalid. Thus, the overall argument is neither sound nor valid, which for an argument is about as bad as it gets. If we look at this as an argument against OA publishing, as it seems to be intended, it fails, but as a rare example of right-wing political rhetoric from a librarian it's kind of fascinating.

Beall approaches OA advocates the same way he claims they approach OA. Referring to the response to an article about predatory OA journals, Beall claims that "the attack on Bohannon was carried out with a near religious fervour. OA advocates will do anything to pro- 
tect the image of open-access" (Beall 2013, 592). If anything has a religious fervour, it's this hyperbolic crusade against $O A$ advocates that paints them all as villains. That predatory $O A$ publishers exist is no evidence whatsoever that OA publishing is inherently bad. Only people who don't reason soundly would make that claim, and perhaps some OA advocates feared that illogical reaction. Perhaps there were OA advocates who attacked Bohannon with religious fervour, although no evidence is given for that. But if there were, that doesn't make all OA advocates into zealots or all OA publishing bad. It's like saying that because some antiOA crusaders produce unsubstantiated attacks on OA advocates, or illogically argue that all OA publishing is bad because some OA publishing is bad, then this somehow proves that $O A$ is inherently good. Neither argument makes much sense.

\section{References}

Beall, Jeffrey. 2013. The Open-Access Movement Is Not Really About Open Access. tripleC: Communication, Capitalism \& Critique 11 (2): 589-597. Accessed July 15, 2014. http://www.triplec.at/index.php/tripleC/article/viewFile/525/514.

Bollier, David. 2013. Did Commercial Journals Use the NYT to Smear Open Access? | David Bollier. http://bollier.org/blog/did-commercial-journals-use-nyt-smear-open-access-0.

Contreras, Jorge L. 2012. Open Access Scientific Publishing and the Developing World. SSRN Scholarly Paper ID 2065887. Rochester, NY: Social Science Research Network. http://papers.ssrn.com/abstract=2065887

Eisen, Michael. 2013. Beall's Litter. It Is NOT Junk http://www.michaeleisen.org/blog/?p=1500.

Esposito, Joseph. 2013. "Parting Company with Jeffrey Beall. The Scholarly Kitchen http://scholarlykitchen.sspnet.org/2013/12/16/parting-company-with-jeffrey-beall/

Harnad, Stevan. 2013. Worldwide Open Access: UK Leadership? Insights 26 (1). Online version: http://eprints.soton.ac.uk/349406/2/fulltext.html

Hirschman, Albert O. 1991. The Rhetoric of Reaction: Perversity, Futility, Jeopardy. Cambridge, MA: Belknap Press.

Kolata, Gina. 2013. For Scientists, an Exploding World of Pseudo-Academia. The New York Times, April 7, sec. Health. http://www.nytimes.com/2013/04/08/health/for-scientists-an-exploding-worldof-pseudo-academia.html

\section{About the Author}

\section{Wayne Bivens-Tatum}

Wayne Bivens-Tatum is the Philosophy and Religion Librarian at Princeton University. He also teaches for the University of Illinois Graduate School for Library and Information Science, contributes to the Library Journal's "Peer to Peer Review" column, and writes the Academic Librarian blog. 